Available online at www.sciencedirect.com

ERRATUM

\title{
Erratum to "Estimation of drag forces caused by natural woody vegetation of different scales"
}

\section{[Journal of Hydrodynamics, 2014, 26(4)]}

JALONEN Johanna, JÄRVELÄ Juha

Department of Civil and Environmental Engineering, Aalto University, Espoo, Finland

\begin{tabular}{ll}
\hline \multicolumn{1}{c}{ ARTICLE INFO } & \multicolumn{1}{c}{ ABSTRACT } \\
\hline $\begin{array}{l}\text { Article history: Received March 5, 2014 } \\
\text { Accepted: April 30, 2014 }\end{array}$ & $\begin{array}{l}\text { This is the erratum to the article [JALONEN Johanna, JÄRVELÄ Juha, } \\
\text { Journal of Hydrodynamics, 2014, 26(4)]. In pages 610 and 621 the drag } \\
\text { coefficients are corrected. }\end{array}$ \\
\hline
\end{tabular}

In pages 610 and 621 the drag coefficients should be:

$$
\begin{aligned}
& C_{D, \text { bulk }}=C_{D \chi} / u_{\chi}^{\chi}, \\
& C_{D, S}=C_{D \chi, S} / u_{\chi, S}^{\chi_{S}}, \\
& C_{D, F}=C_{D \chi, F} / u_{\chi, F}^{\chi_{F}},
\end{aligned}
$$

and all have the unit of $(\mathrm{m} / \mathrm{s})^{-\chi}$.

Subsequently, the sentence in page 610 below Eq.(8) should read: "The drag coefficients correspond to $C_{D, S}=C_{D \chi, S} / u_{\chi, S}^{\chi_{S}}$ and $C_{D, F}=C_{D \chi, F} / u_{\chi_{, F}}^{\chi_{F}}$, and have units of $(\mathrm{m} / \mathrm{s})^{-\chi_{S}}$ and $(\mathrm{m} / \mathrm{s})^{-\chi_{F}}$, respectively."

\section{Reference}

[1] JALONEN Johanna, JÄRVELÄ Juha. Journal of Hydrodynamics, 2014, 26(4).

DOI of original article: 10.1016/S1001-6058(14)60068-8.

E-mail address: johanna.jalonen@aalto.fi 